\title{
Gênero e sexualidade: pedagogias contemporâneas
}

Guacira Lopes Louro *

Resumo: Gênero e sexualidade são construídos através de inúmeras aprendizagens e práticas, empreendidas por um conjunto inesgotável de instâncias sociais e culturais, de modo explícito ou dissimulado, num processo sempre inacabado. Na contemporaneidade, essas instâncias multiplicaram-se e seus ditames são, muitas vezes, distintos. Nesse embate cultural, torna-se necessário observar os modos como se constrói e se reconstrói a posição da normalidade e a posição da diferença, e os significados que lhes são atribuídos.

Palavras-chave: gênero; sexualidade; pedagogias culturais; norma; diferença.

Gender and sexuality: contemporary pedagogies

Abstract: Gender and sexuality are made up of several practices and learning methods, through countless social and cultural instances, in an endless process. These instances have been multiplied and their principles are often different. In this cultural battle, we must observe how normality is constructed and re-constructed, and how differences are considered and treated.

Key words: gender; sexuality; cultural pedagogies; norm; difference.

Há mais de cinquienta anos, Simone de Beauvoir sacudiu a poeira dos meios intelectuais com a frase Ninguém nasce mulher: torna-se mulher. A expressão causou impacto e ganhou o mundo. Mulheres das mais diferentes posiçôes, militantes e estudiosas passaram a repeti-la para indicar que seu modo de ser e de estar no mundo não resultava de um ato único, inaugural, mas que, em vez disso, constituía-se numa construção. Fazer-se mulher dependia das marcas, dos gestos, dos comportamentos, das preferências e dos desgostos que lhes eram ensinados e reiterados, cotidianamente, conforme normas e valores de uma dada cultura.

Muita coisa mudou desde o final dos anos 1940 (quando Beauvoir publicou o seu Segundo sexo) e o fazer-se mulher transformou-se, pluralizou-se, de

* Professora Titular aposentada da Universidade Federal do Rio Grande do Sul (UFRGS). Brasil. Colaboradora convidada da mesma universidade, no Programa de Pós-Graduação em Educação, Linha de Pesquisa Educação, Sexualidade e Relações de Gênero, Fundadora do GEERGE (Grupo de Estudos de Educação e Relaçōes de Gênero).guacira.louro@gmail.com 
um modo tal que talvez nem mesmo a filósofa ousasse imaginar. Mas a frase ficou. De certa forma, pode ser tomada como uma espécie de gatilho provocador de um conjunto de reflexões e teorizações, exuberante e fértil, polêmico e disputado, não só no campo do feminismo e dos estudos de gênero, como também no campo dos estudos da sexualidade. A frase foi alargada, é claro, passando a ser compreendida também no masculino. Sim, decididamente, fazer de alguém um homem requer, de igual modo, investimentos continuados. Nada há de puramente "natural" e "dado" em tudo isso: ser homem e ser mulher constituem-se em processos que acontecem no âmbito da cultura.

Ainda que teóricas e intelectuais disputem quanto aos modos de compreender e atribuir sentido a esses processos, elas e eles costumam concordar que não é o momento do nascimento e da nomeação de um corpo como macho ou como fêmea que faz deste um sujeito masculino ou feminino. A construção do gênero e da sexualidade dá-se ao longo de toda a vida, continuamente, infindavelmente.

Quem tem a primazia nesse processo? Que instâncias e espaços sociais têm o poder de decidir e inscrever em nossos corpos as marcas e as normas que devem ser seguidas? Qualquer resposta cabal e definitiva a tais questôes será ingênua e inadequada. A construção dos gêneros e das sexualidades dá-se através de inúmeras aprendizagens e práticas, insinua-se nas mais distintas situaçôes, é empreendida de modo explícito ou dissimulado por um conjunto inesgotável de instâncias sociais e culturais. É um processo minucioso, sutil, sempre inacabado. Família, escola, igreja, instituiçôes legais e médicas mantêm-se, por certo, como instâncias importantes nesse processo constitutivo. Por muito tempo, suas orientaçôes e ensinamentos pareceram absolutos, quase soberanos. Mas como esquecer, especialmente na contemporaneidade, a sedução e o impacto da mídia, das novelas e da publicidade, das revistas e da internet, dos sites de relacionamento e dos blogs? Como esquecer o cinema e a televisão, os shopping centers ou a música popular? Como esquecer as pesquisas de opinião e as de consumo? E, ainda, como escapar das câmeras e monitores de vídeo e das inúmeras máquinas que nos vigiam e nos "atendem" nos bancos, nos supermercados e nos postos de gasolina? Vivemos mergulhados em seus conselhos e ordens, somos controlados por seus mecanismos, sofremos suas censuras. As proposições e os contornos delineados por essas múltiplas instâncias nem sempre são coerentes ou igualmente autorizados, mas estão, inegavelmente, espalhados por toda a parte e acabam por constituir-se como potentes pedagogias culturais.

"Especialistas" das mais diversas áreas dizem-nos o que vestir, como andar, o que comer (como e quando e quanto comer), o que fazer para conquistar (e para manter) um parceiro ou parceira amoroso/a, como se apresentar para con- 
seguir um emprego (ou para ir a uma festa), como "ficar de bem com a vida", como se mostrar sensual, como aparentar sucesso, como... ser.

Dieta S.O.S. Barriga chapada. Montamos um cardápio para você desfilar no verão com abdômen sequinho. Confira e comeceján

Mude o visual e ganhe atitude.

Como conquistar a gata dos seus sonhos. Ensinamos passo-apasso as técnicas de aproximação e de conquista.

Sabia que você pode substituir a flacidez por músculos? Discipline-se, adquira novos hábitos.

Na festa mais "descolada" da temporada, aprenda com aqueles que já sabem tudo o que vai rolar na nova estação.

Conselhos e palavras de ordem interpelam-nos constantemente, ensinamnos sobre saúde, comportamento, religião, amor, dizem-nos o que preferir e o que recusar, ajudam-nos a produzir nossos corpos e estilos, nossos modos de ser e de viver. Algumas orientaçôes provêm de campos consagrados e tradicionalmente reconhecidos por sua autoridade, como o da medicina ou da ciência, da família, da justiça ou da religião. Outras parecem "surgir" dos novos espaços ou ali ecoar. Não há uniformidade em suas diretrizes. Ainda que normas culturais de há muito assentadas sejam reiteradas por várias instâncias, é indispensável observar que, hoje, multiplicaram-se os modos de compreender, de dar sentido e de viver os gêneros e a sexualidade.

Transformaçôes são inerentes à história e à cultura, mas, nos últimos tempos, elas parecem ter se tornado mais visíveis ou ter se acelerado. Proliferaram vozes e verdades. Novos saberes, novas técnicas, novos comportamentos, novas formas de relacionamento e novos estilos de vida foram postos em ação e tornaram evidente uma diversidade cultural que não parecia existir. Cada vez mais perturbadoras, essas transformaçōes passaram a intervir em setores que haviam sido, por muito tempo, considerados imutáveis, trans-históricos e universais.

Em poucos anos, tornaram-se possíveis novas tecnologias reprodutivas, a transgressão de categorias e de fronteiras sexuais e de gênero, além de instigantes articulações corpo-máquina. Desestabilizaram-se antigas e sólidas certezas, subverteram-se as formas de gerar, de nascer, de crescer, de amar ou de morrer. Informações e pessoas até então inatingíveis tornaram-se acessíveis por um simples toque de computador. Relações afetivas e amorosas passaram a ser vividas virtualmente; relações que desprezam dimensões de espaço, de tempo, de gênero, de sexualidade, de classe ou de raça; relaçôes nas quais o anonimato e a

1. Algumas dessas orientaçōes foram extraídas das ediçōes de dezembro de 2007 das revistas Nova e Boa Forma (Ed. Abril). 
troca de identidade são parte do jogo. Impossível desprezar os efeitos de todas essas transformaçóes: elas constituem novas formas de existência para todos, mesmo para aqueles que, num primeiro momento, não as experimentam de modo direto.

Como parte de tudo isso, vem se afirmando uma nova política cultural, a política de identidades. Muito especialmente a partir dos anos 1960, jovens, estudantes, negros, mulheres, as chamadas "minorias" sexuais e étnicas passaram a falar mais alto, denunciando sua inconformidade e seu desencanto, questionando teorias e conceitos, derrubando fórmulas, criando novas linguagens e construindo novas práticas sociais. Uma série de lutas ou uma luta plural, protagonizada por grupos sociais tradicionalmente subordinados, passava a privilegiar a cultura como palco do embate. Seu propósito consistia, pelo menos inicialmente, em tornar visíveis "outros" modos de viver, os seus próprios modos: suas estéticas, suas éticas, suas histórias, suas experiências e suas questões. Desencadeava-se uma luta que, mesmo com distintas caras e expressōes, poderia ser sintetizada como a luta pelo direito de falar por si e de falar de si. Esses diferentes grupos, historicamente colocados em segundo plano pelos grupos dominantes, estavam e estão empenhados, fundamentalmente, em se autorepresentar.

"A cultura", diz Stuart Hall "é agora um dos elementos mais dinâmicos - e mais imprevisíveis - da mudança histórica do novo milênio". Daí porque não deve nos surpreender que "as lutas pelo poder sejam, crescentemente, simbólicas e discursivas, ao invés de tomar, simplesmente uma forma física e compulsiva, e que as próprias políticas assumam progressivamente a feição de uma ‘política cultural'”... (Hall, 1997, p. 20).

Esse tipo de luta requer "armas" peculiares. Supõe estratégias mais sutis e engenhosas. Talvez por isso a alguns escape a força dos embates culturais. Mas os movimentos sociais organizados (dentre eles o movimento feminista e os das "minorias" sexuais) compreenderam, desde logo, que o acesso e o controle dos espaços culturais, como a mídia, o cinema, a televisão, os jornais, os currículos das escolas e universidades, eram fundamentais. A voz que ali se fizera ouvir, até então, havia sido a do homem branco heterossexual. Ao longo da história, essa voz falara de um modo quase incontestável. Construíra representações sociais que tiveram importantes efeitos de verdade sobre todos os demais. Passamos, assim, a tomar como verdade que as mulheres se constituíam no "segun-

2. A expressão "minoria" não pretende se referir a quantidade numérica, mas sim a uma atribuição valorativa que é imputada a um determinado grupo a partir da ótica dominante. Conforme a revista La Gandhi Argentina (1 998), "as minorias nunca poderiam se traduzir como uma inferioridade numérica, mas sim como maiorias silenciosas que, ao se politizar, convertem o gueto em território e o estigma em orgulho - gay, étnico, de gênero". 
do sexo" ou que gays, lésbicas, bissexuais eram sujeitos de sexualidades "desviantes". Por tudo isso, colocava-se, como uma meta urgente para os grupos submetidos, apropriar-se dessas instâncias culturais e aí inscrever sua própria representação e sua história, pôr em evidência as questões de seu interesse. A luta no terreno cultural mostrava-se (e se mostra), fundamentalmente, como uma luta em torno da atribuição de significados - significados produzidos em meio a relações de poder.

Esse embate, como qualquer outro embate cultural, é complexo exatamente porque está em contínua transformação. No terreno dos gêneros e da sexualidade, o grande desafio, hoje, parece não ser apenas aceitar que as posições se tenham multiplicado, então, que é impossível lidar com elas a partir de esquemas binários (masculino/feminino, heterossexual/homossexual). O desafio maior talvez seja admitir que as fronteiras sexuais e de gênero vêm sendo constantemente atravessadas e - o que é ainda mais complicado - admitir que o lugar social no qual alguns sujeitos vivem é exatamente $a$ fronteira. A posição de ambiguiidade entre as identidades de gênero e/ou sexuais é o lugar que alguns escolheram para viver (Louro, 2004).

A visibilidade que todos esses "novos" grupos adquiriram pode ser, eventualmente, interpretada como um atestado de sua progressiva aceitação. Contudo, nem mesmo a exuberância das paradas da diversidade sexual, das feiras mix, dos festivais de filmes "alternativos" permite ignorar a longa história de marginalização e de repressão que esses grupos enfrentaram e ainda enfrentam. Não podemos tomar de modo ingênuo essa visibilidade. Se, por um lado, alguns setores sociais passam a demonstrar uma crescente aceitação da pluralidade sexual e, até mesmo, passam a consumir alguns de seus produtos culturais, por outro lado, setores tradicionais renovam (e recrudescem) seus ataques, realizando desde campanhas de retomada dos valores tradicionais da família até manifestaçôes de extrema agressão e violência física.

Hoje, tal como antes, a sexualidade permanece como alvo privilegiado da vigilância e do controle das sociedades. Ampliam-se e diversificam-se suas formas de regulação, multiplicam-se as instâncias e as instituiçôes que se autorizam a ditar-lhe normas. Foucault certamente diria que proliferam cada vez mais os discursos sobre o sexo e que as sociedades continuam produzindo, avidamente, um "saber sobre o prazer", ao mesmo tempo que experimentam o "prazer de saber" (Foucault, 1988).

A sutileza do embate cultural requer um olhar igualmente sutil. Há que perceber os modos como se constrói e se reconstrói a posição da normalidade e a posição da diferença, porque, afinal, é disso que se trata. Em outras palavras, é preciso saber quem é reconhecido como sujeito normal, adequado, sadio e quem se diferencia desse sujeito. As noçôes de norma e de diferença tornaram- 
se particularmente relevantes na contemporaneidade. É preciso refletir sobre seus possíveis significados.

A norma, ensina-nos Foucault, está inscrita entre as "artes de julgar", ela é um princípio de comparação. Sabemos que tem relação com o poder, mas sua relação não se dá pelo uso da força, e sim por meio de uma espécie de lógica que se poderia quase dizer que é invisível, insidiosa (Ewald, 1993). A norma não emana de um único lugar, não é enunciada por um soberano, mas, em vez disso, está em toda parte. Expressa-se por meio de recomendaçóes repetidas e observadas cotidianamente, que servem de referência a todos. Daí por que a norma se faz penetrante, daí por que ela é capaz de se "naturalizar".

Quanto à diferença, é possível dizer que ela seja um atributo que só faz sentido ou só pode se constituir em uma relação. A diferença não pré-existe nos corpos dos indivíduos para ser simplesmente reconhecida; em vez disso, ela é atribuída a um sujeito (ou a um corpo, uma prática, ou seja lá o que for) quando relacionamos esse sujeito (ou esse corpo ou essa prática) a um outro que é tomado como referência. Portanto, se a posição do homem branco heterossexual de classe média urbana foi construída, historicamente, como a posição-de-sujeito ou a identidade referência, segue-se que serão "diferentes" todas as identidades que não correspondam a esta ou que desta se afastem. A posição "normal" é, de algum modo, onipresente, sempre presumida, e isso a torna, paradoxalmente, invisível. Não é preciso mencioná-la. Marcadas serão as identidades que dela diferirem.

Continuamente, as marcas da diferença são inscritas e reinscritas pelas políticas e pelos saberes legitimados, reiteradas por variadas práticas sociais e pedagogias culturais. Se, hoje, as classificações binárias dos gêneros e da sexualidade não mais dão conta das possibilidades de práticas e de identidades, isso não significa que os sujeitos transitem livremente entre esses territórios, isso não significa que eles e elas sejam igualmente considerados.

Portanto, antes de simplesmente assumir noçôes "dadas" de normalidade e de diferença, parece produtivo refletir sobre os processos de inscrição dessas marcas. Não se trata de negar a materialidade dos corpos, mas sim de assumir que é no interior da cultura e de uma cultura específica que características materiais adquirem significados. Como isso tudo aconteceu e acontece? Através de que mecanismos? Se em tudo isso estão implicadas hierarquias e relações de poder, por onde passam tais relaçôes? Como se manifestam? Não, a diferença não é natural, mas sim naturalizada. A diferença é produzida através de processos discursivos e culturais. A diferença é "ensinada".

Aprendemos a viver o gênero e a sexualidade na cultura, através dos discursos repetidos da mídia, da igreja, da ciência e das leis e também, contemporaneamente, através dos discursos dos movimentos sociais e dos múltiplos dispositi- 
vos tecnológicos. As muitas formas de experimentar prazeres e desejos, de dar e de receber afeto, de amar e de ser amada/o são ensaiadas e ensinadas na cultura, são diferentes de uma cultura para outra, de uma época ou de uma geração para outra. E hoje, mais do que nunca, essas formas são múltiplas. As possibilidades de viver os gêneros e as sexualidades ampliaram-se. As certezas acabaram. Tudo isso pode ser fascinante, rico e também desestabilizador. Mas não há como escapar a esse desafio. O único modo de lidar com a contemporaneidade é, precisamente, não se recusar a vivê-la.

\section{Referências bibliográfıcas}

BEAUVOIR, Simone. O segundo sexo. Rio de Janeiro: Nova Fronteira, 1980.

EWALD, François. Foucault: A norma e o direito. Lisboa: Vega, 1993.

FOUCAULT, Michel. História da sexualidade 1. A vontade de saber. Rio de Janeiro: Graal, 1988.

HALL, Stuart. A centralidade da cultura: notas sobre as revoluções de nosso tempo. Educação \& Realidade.v. 22, n. 2, jul./dez. 1997.

La Gandhi Argentina. Editorial, ano 2, n. 3, nov. 1998.

LOURO, Guacira Lopes. Um corpo estranho: Ensaios sobre sexualidade e teoria queer. Belo Horizonte: Autêntica, 2004.

Recebido em maio de 2007 e aprovado em agosto de 2007. 